\title{
Synergistic Effect of Saikosaponin a and Albiflorin Against Corticosterone-Induced Neuro-Injury in PC12 Cells via Regulation of TCA Cycle, Purine Metabolism, and Glutamate Metabolism
}

\section{Xiao Li}

Shanxi University

Ruihong Hou

Shanxi Medical University

Hao Shi

Shanxi University

Xuemei Qin

Shanxi University

Yanfei Wu

Shanxi Medical University

\section{Xingkang Wu}

Shanxi University

Junsheng Tian

Shanxi University

Xiaoxia Gao

Shanxi University

\section{Guanhua Du}

Chinese Academy of Medical Sciences and Peking Union Medical College

\section{Yuzhi Zhou ( $\nabla$ zhouyuzhi@sxu.edu.cn )}

Shanxi University https://orcid.org/0000-0002-2034-5626

Original Article

Keywords: Saikosaponin A, Albiflorin, Synergistic, Neuroprotective, Metabolic disorders

Posted Date: February 3rd, 2021

DOl: https://doi.org/10.21203/rs.3.rs-159289/v1

License: (c) (i) This work is licensed under a Creative Commons Attribution 4.0 International License. Read Full License 
Page 2/24 


\section{Abstract}

The combination of Radix Bupleuri - Radix Paeoniae alba is one of the most approbated herb pairs in traditional Chinese medicine (TCM) formula for curing depression. Saikosaponin A (SSA) and albiflorin (AF) are major bioactive compounds of Radix Bupleuri and Radix Paeoniae alba respectively, which possess antidepressant effects in pharmacological experiments. However, whether SSA and AF have synergistic neuroprotective effects and the synergistic mechanism is still unknown. The present study employed the corticosterone-induced PC12 cells neuro-injury model to assess the protective effect of SSA and $\mathrm{AF}$, alone and in combination, and the synergistic effect was analyzed using three mathematical models. Meanwhile, the cell metabolomics was used to detect the effects on metabolite regulation of SSA and AF, alone and in combination. According to the results of cell metabolomics, the vital cell transduction pathway related to the crucial cell metabolic pathways were selected. Furthermore, the key metabolites, metabolic enzymes, and cellular markers were verified by ELISA and Western blotting. The results showed that the combination of SSA and AF has a synergistic neuroprotective effect. Besides, the combination could regulate more metabolites (16) than a single agent $(12 \& 10)$ and possessed a stronger adjustment effect on metabolites. Correspondingly, the combination regulated more metabolism pathways (7) than alone agents ( 3 \& 5). Furthermore, the TCA cycle, purine metabolism, and glutamate metabolism were selected as crucial metabolism pathways. The results showed that the TCA cycle disorder was regulated by SSA and AF via improving mitochondrial function. The purine metabolism disorder was regulated by SSA via inhibition xanthine oxidase (XOD) activity and the glutamate metabolism disorder was regulated by AF via inhibition glutaminase (GLS) activity. Moreover, the oxidative stress induced by the purine metabolism disorder was attenuated by SSA via a reduction in the ROS level. Additionally, the inflammation induced by the oxidative stress was attenuated by the SSA and AF via inhibition of the NLRP3 protein expression. This study for the first time demonstrated the synergistic neuroprotective effect of SSA and AF, and the synergistic mechanism was involved in metabolic disorders regulation.

\section{Introduction}

Depression is one of the most significant public disease burdens in the world [1]. Roughly one-third of the depression patients did not remit after 1 year of treatment with pharmacotherapy [2]. Most antidepressants are single-target drugs and have many adverse effects, so the development of multiple targets, high-efficiency, and low toxicity anti-depressants is a pressing task [3-5].

Radix Bupleuri has been used for centuries in TCM, which possess immunomodulatory, antiinflammatory, and antidepressant effects [6]. As major bioactive compounds separated from Radix Bupleuri, saikosaponins have numerous biological activities, including anti-inflammatory, antidepressant, and neuroprotective activity [7]. Saikosaponin A (SSA), one of the major saikosaponins, has been demonstrated to exhibit antidepression and neuroprotective activity [8-10]. While, Radix Paeoniae Alba, a core medicinal product in China, possesses anti-inflammatory and anti-depression activities [11, 12]. 
Albiflorin (AF), one of the major active compounds separated from Radix Paeoniae Alba, exhibits antidepressant, and neuroprotective activity $[13,14]$.

The combination of Radix Bupleuri and Radix Paeoniae alba is commonly used in many TCM formulas for curing depression, such as Xiaoyao San [15], Sini San [16], etc. According to TCM theory, Radix Bupleuri and Radix Paeoniae alba is the "Sovereign" herb and "Minister" herb respectively [17]. The "Sovereign" herb is the predominant medicine used for therapy disease and the "Minister" herb has synergistic effects with the "Sovereign" herb [18]. And, previous experimental studies have suggested that both Radix Bupleuri and Radix Paeoniae alba possess antidepressant effects respectively, and the combination can strengthen the anti-depressant effects [19-22]. Based on previous research, we hypothesis that the SSA and AF combination may display synergistic neuroprotective effects.

As the profiling of metabolites in an organism, metabolomics is a useful tool for biomarker discovery. Owing to the sensitivity of metabolomics, slight alterations in biological pathways can be observed to discover the pathological mechanism [23]. In recent years, considerable researchers have experimented with the metabolomics study of PC12 cell injury by corticosterone [24]. Studies have shown that corticosterone, $A \beta_{25-35}$, and (2R,6R)-Hydroxynorketamine could induce disturbance of cellular metabolic, including purine metabolism, glutamate metabolism, and TCA cycle, etc. in PC12 cell [25-28]. Meanwhile, metabolomics is an effective tool to elucidate the potential compatibility mechanisms of traditional Chinese medicine [29].

In this study, the Chou-Talalay model, Loewe model, and HAS model were used to assess the synergistic neuroprotective effect of SSA and AF. And, the metabolic profile and differential metabolites were studied by the LC-MS metabolomics. Furthermore, the vital cell transduction pathway related to the crucial cell metabolic pathways were experimental verification. The present study was the first to research the synergistic neuroprotective effects and mechanisms of SSA and AF.

\section{Materials And Methods}

\subsection{Chemicals and reagents}

Saikosaponin A (SSA) and albiflorin (AF) ( $\geqq 98 \%$, Chengdu Pufei De, China). Corticosterone, MTT, and DMSO ( $\geqq 98.5 \%, \geqq 98 \%$, $\geqq 99.7 \%$, Sigma-Aldrich Co.; St. Louis, USA). Febuxostat (100.00\%) and BPTES (98.00 \%) (Topscience Co., Ltd., China). Fetal bovine serum (Sijiqing; Zhejiang Tianhang Biotechnology Co., Ltd., China). RPMI-1640 and Annexin V-FITC/PI staining kit (Sangon Biotech Co., Ltd, China). LDH leakage diagnostic kit and Hoechst 33342 staining kit (Nanjing Jiancheng Bioengineering Institute, China). MimiColor Protein Marker (Minibio Technology Co., Ltd, China). $\beta$-actin, NLRP3 (Biosynthesis Biotechnology Inc, China). Acetonitrile and methanol (Thermo Fisher, USA). Rat IL-1 $\beta$, IL-6, TNF- $a$, XOD, xanthine, GLS, and glutamate ELISA assay kit (AndyGenen Biotechnology Co., LTD, China).

\subsection{Cell culture and treatment}


Differentiated PC12 cells (Cell Bank of Chinese Academy of Sciences, China) were cultured in RPMI-1640 with $10 \%$ fetal bovine serum, in a humidified $95 \%$ atmosphere containing $5 \% \mathrm{CO}_{2}$ at $37{ }^{\circ} \mathrm{C}$. PC12 cells were divided into the control group, corticosterone-induced group, and corticosterone-induced plus drug treatment groups. PC12 cells were seeded on $0.01 \%$ poly-L-polylysine coated 96 -well plates, 6 -well plates, and $100 \mathrm{~mm}$ dishes with $2 \times 10^{4} \mathrm{per} /$ well, $4 \times 10^{5} \mathrm{per} /$ well, and $2 \times 10^{6} \mathrm{per} /$ dishes. After $24 \mathrm{~h}$ incubation, the PC12 cells were co-incubated with different concentrations of SSA, AF, alone and in combination, and corticosterone $(400 \mu \mathrm{mol} / \mathrm{L})$ for another $24 \mathrm{~h}$.

\subsection{MTT-based cell viability assay}

The cell viability was assessed using an MTT assay. Cells were seeded in 96-well plates for $24 \mathrm{~h}$ and treated with drugs for $24 \mathrm{~h}$ before adding MTT. The cells were then incubated with MTT $(0.5 \mathrm{mg} / \mathrm{mL})$ for another $4 \mathrm{~h}$ at $37^{\circ} \mathrm{C}$. Thereafter, absorbance at $570 \mathrm{~nm}$ was measured in a microplate reader (Tecan, USA).

\subsection{Evaluation of the Synergistic Effect}

The alone neuroprotective effect of SSA and AF were tested at concentrations as, $0.156,0.3125,0.625$, $1.25,2.5,5 \mu \mathrm{mol} / \mathrm{L}$ and $1.56,3.125,6.25,12.5,25,50 \mu \mathrm{mol} / \mathrm{L}$. The combination doses were determined based on the optimal neuroprotective result of the alone treatment groups. The twenty-five combinations of SSA and AF to identify the optimal synergistic dose and dose range. The combination treatment cell viability results were further analyzed with Chou-Talalay, Loewe, and HAS model analysis to determine the synergistic effect. Chou-Talalay model analysis was carried out in CompuSyn software [30]. CompuSyn program was used to compute a combination index $(\mathrm{Cl})$ for drug combinations studied. The resulting $\mathrm{Cl}$ offers a quantitative definition for additive effect $(\mathrm{Cl}=1)$, synergism $(\mathrm{Cl}<1)$, and antagonism $(\mathrm{Cl}>1)$ in drug combinations. Loewe and HAS model analysis was carried out in Combenefit software [31]. Combenefit software was used to fit with a dose-response surface, resulting in a synergy distribution in concentration space. The optimal synergistic combination dose and the alone doses were used in the following experiments to identify the possible synergistic neuroprotective mechanism.

\subsection{LDH leakage assay}

The cellular toxicity was detected with the release of LDH. According to the manufacturer's instructions. After drug treatment, the supernatant and cell lysates were collected for analysis of LDH leakage.

\subsection{Detection of cell apoptotic by Hoechst staining and Annexin V-FITC/PI staining}

The deformation of apoptosis cell nuclei was detected using the Hoechst staining. According to the manufacturers' instructions, the fluorescence image was visualized by inverted IX71 fluorescence microscopy (Nikon, Japan).

The apoptosis cells were measured by Annexin V-FITC/PI staining. The cells were harvested and incubated with Annexin V-FITC/PI (1x) working solution for $15 \mathrm{~min}$. Apoptosis cells were quantified by 
using FACS Calibur II flow cytometer (BD Biosciences, USA).

\subsection{Metabolomics analysis}

Metabolomics analysis was performed as described in our previous study [32]. Briefly, the harvested cells were lysed with extraction solvent ( methanol: water $=4: 1, V / V$ ), and centrifuged to get supernatant and freeze-drying. Then the extract was dissolved with $100 \mu \mathrm{L}$ extraction solvent, and a quality control (QC) sample was prepared from $10 \mu \mathrm{L}$ of each test sample. Using Thermo-Fisher Dionex UltiMate 3000 UHPLC-Q Exactive Orbitrap-MS to acquire LC-MS raw data. The PCA, PLS-DA, and OPLS-DA were conducted by SIMCA-P 14.1 software. The differential metabolites were selected, according to VIP values $(\mathrm{VIP}>1)$ and T-test $(P<0.05)$. Pathway analysis was conducted with MetaboAnalyst [33].

\subsection{Measurement of xanthine, glutamate, IL-1 $\beta$, IL-6, TNF- $a$ levels and XOD, GLS activity}

The cells were collected and centrifuged to obtain a cell pellet and supernatant and stored at $-80^{\circ} \mathrm{C}$ until required for analysis. The level of xanthine, glutamate, IL-1 $13, \mathrm{IL}-6, \mathrm{TNF}-\mathrm{a}$, and the activity of XOD, GLS was determined by commercial assay kits.

\subsection{Measurement of MMP and Ros level}

The JC-1 (Beyotime Biotechnology, China) was used to determine the changes in MMP. Briefly, following the JC-1 assay kit manufacturer's instructions, cells were harvested and incubated with $\mathrm{JC}-1$ (1x) for $30 \mathrm{~min}$ at $37^{\circ} \mathrm{C}$ in the dark. Then cells were flushed twice with JC-1 buffer (1x). The MMP decline rates were analyzed by a flow cytometer and the staining image was also visualized by fluorescence microscopy.

The DCFH-DA (Beyotime Biotechnology, China) was used to detect the ROS level. Briefly, cells were stained with $10 \mathrm{mmol} / \mathrm{L} \mathrm{DCFH-DA}$ for $30 \mathrm{~min}$ at $37^{\circ} \mathrm{C}$ in the dark. The ROS increase rates were analyzed by a flow cytometer and the staining image was also visualized by fluorescence microscopy.

\subsection{Western blot analyses}

Metabolomics analysis was performed as described in our previous study [32]. Briefly, cells were harvested and the total protein was lysed with RIPA lysis buffer. The fifty micrograms were separated by electrophoresis and transferred to PVDF membranes. The membranes were blocked with Tris-buffered saline containing $5 \%(\mathrm{w} / \mathrm{v})$ non-fat milk and incubated with the primary antibodies. Then signals of bound antibodies were identified with enhanced chemiluminescence.

\subsection{Statistical Analysis}

Statistical analysis was performed by one-way analysis of variance (ANOVA) followed by a Dunnett post hoc test and presented as means \pm SD (SPSS 19.0). A P-value $<0.05$ was considered a statistically significant difference. 


\section{Results}

\subsection{The neuroprotection effect of SSA and AF}

The effect of SSA and AF alone were investigated in PC12 cells. In Fig. 1A/B, 0.312-5 $\mu \mathrm{mol} / \mathrm{L}$ of SSA and 3.12-100 $\mu \mathrm{mol} / \mathrm{L}$ of AF shown no obvious effects. Therefore, SSA and AF concentration of $0.156,0.312$, $0.625,1.25,2.5,5 \mu \mathrm{mol} / \mathrm{L}$ and $1.56,3.12,6.25,12.5,25,50 \mu \mathrm{mol} / \mathrm{L}$ were used to evaluate the neuroprotective effects. As shown in Figure C/D, SSA and AF treatment dose-dependently prevented the decrease in corticosterone-induced cell viability with maximum protective effects at $2.5 \mu \mathrm{mol} / \mathrm{L}$ and $25 \mu \mathrm{mol} / \mathrm{L}$ respectively.

\subsection{The synergistic neuroprotection effect of SSA and AF}

To examine whether the combination of SSA and AF would have a synergistic effect. To this end, corticosterone-induced PC12 cells were treated with indicated concentrations of SSA and AF, alone and in combination, and the cell viability was analyzed using MTT assay. As shown in Fig. 2A/B/C, Cl values were determined using the CompuSyn software. $\mathrm{Cl}<1.0$ for virtually all conditions (except one condition for SSA and AF combination) indicated synergism between SSA and AF, and the optimal synergistic dose was $2.5 \mu \mathrm{mol} / \mathrm{L}$ of SSA and $25 \mu \mathrm{mol} / \mathrm{L}$ of AF. The interaction relationship between SSA and AF was further studied using Combenefit programs by using two "classical" mathematical models (Loewe and HSA). The output is composed of scores that capture information about the synergy distribution and the synergy levels were depicted as surface plots. As shown in Fig. 2D/E/F/G/H/I (D/E/F - Loewe model, $\mathrm{G} / \mathrm{H} / \mathrm{I}-\mathrm{HAS}$ model), the synergistic dose range was $1.25-2.5 \mu \mathrm{mol} / \mathrm{L}$ of SSA and $12.5-25 \mu \mathrm{mol} / \mathrm{L}$ of AF. Those three mathematical models agree in the overall evaluation of SSA and AF combination activity against corticosterone-induced neuro-injury in PC12 cells. These results revealed that the combination of $\mathrm{SSA}$ and $\mathrm{AF}$ has a synergistic effect. Thus, the concentrations of $2.5 \mu \mathrm{mol} / \mathrm{L}$ (SSA) and $25 \mu \mathrm{mol} / \mathrm{L}$ (AF) were chosen in subsequent experiments.

For further evaluation of the neuroprotection effect of SSA and AF, alone and in combination, the LDH assay, Hoechst 33342 staining assay, and Annexin V-FITC/PI flow cytometry assay was implemented. As depicted in Fig. 3A, the cells incubated with corticosterone $(400 \mu \mathrm{mol} / \mathrm{L})$ exhibited an increased level of $\mathrm{LDH}$ release compared with the control group $(\mathrm{P}<0.01)$, SSA $(2.5 \mu \mathrm{mol} / \mathrm{L}), \mathrm{AF}(25 \mu \mathrm{mol} / \mathrm{L})$ pretreatment resulted in a reduction of the $L D H$ release. Moreover, when SSA was combined with AF, significantly decreases in LDH release $(p<0.01)$. And, the effect of the SSA and AF combination was significantly better than SSA or AF alone $(p<0.01, p<0.01)$. Figure 3B/C/D showed that the population of apoptotic cells after corticosterone treatment was significantly increased relative to the control group. However, these changes were markedly reversed by SSA, AF, and SSA and AF combination $(p<0.01, p<0.01, p<$ 0.01). Especially that SSA and AF combination treatment dramatically reduced the population of apoptotic cells as compared to the SSA and AF alone $(p<0.01)$. These results further revealed that the combination of SSA and AF has synergistic effects. 


\subsection{SSA and AF protected corticosterone-induced neuro- injury by regulating metabolic disorders}

The metabolite profile of PC12 cells was obtained by LC-MS in positive and negative ion modes; the total peak intensity chromatograms of the cell sample was shown in Figure S1. The PCA score plots observed that the metabolic distribution of the model group was different from the control group. Besides, the QC group gathered together showed that the instrument was stable (Fig. 4A). The PLS-DA model was validated by the permutation test (Fig. 4B). The $R^{2} X(0.633), R^{2} Y(0.997)$, and $Q^{2}(0.993)$ showed that the OPLS-DA model established had good quality and predictive performance. The OPLS-DA score plots observed that significant separations between the model and the control group (Fig. 4C). The S-plots of OPLS-DA revealed a variety of metabolites (Fig. 4D). Future, the OPLS-DA score plots observed that all groups were separated. Among them, the drug treatment groups were closer to the control group than the model group, suggesting that the metabolic disturbances induced by corticosterone were reversed after drug treatment. Moreover, the combination group has a better separation effect than an alone agent (Fig. 4E).

According to VIP values $(>1.0)$ and T-test $(P<0.05), 30$ differential metabolites were screened out (Table S1). Among them, 14 increased metabolites and 16 decreased metabolites in the model group. The SSA, $\mathrm{AF}$, and the combination of SSA and AF could regulate 12, 10, and 16 differential metabolites respectively, and the combination has a stronger regulation effect on metabolites than an alone agent (Fig. 4F, Fig. 2S). The hierarchical clustering analysis heatmap observed that the combination group separated from the model group and gathered with the control group (Fig. 4G). As a result, these metabolites could be significantly regulated, and the metabolic disorders were ameliorated in corticosterone-induced PC12 cell injury after drug treatment. These differential metabolites were imported into MetaboAnalyst to explore the potential neuroprotection mechanisms. The metabolic pathways were selected according to the pathway impact Values $>0$. The results showed that the combination regulated more metabolic pathways (7) than an alone agent ( 3 \& 5) (Fig. 5A/B/C/D). The TCA cycle, purine metabolism, and glutamate metabolism were selected as the crucial metabolic pathways according to the number of metabolites contained in metabolic pathways and the relationship between metabolic pathways [34] (Fig. 5E).

\subsection{SSA and AF protected corticosterone-induced neuro- injury by regulating TCA cycle disorders}

To clarify the regulation mechanisms of SSA and AF, alone and in combination, on the TCA cycle, the mitochondrial function was detected. Exposure to corticosterone $(400 \mu \mathrm{mol} / \mathrm{L})$ significantly reduced the level of mitochondrial membrane potential. In contrast, pretreatment with SSA, AF, and SSA and AF combination significantly reversed the phenomenon induced by corticosterone, meanwhile, the effect of the SSA and AF combination was significantly better than SSA or AF alone (Fig. 6A/B/C). 


\subsection{SSA protected corticosterone-induced neuro-injury by regulating purine metabolism disorders}

To evaluate the regulation effects of SSA and AF, alone and in combination, on purine metabolism, the level of xanthine, and the activity of XOD in cells were detected. Exposure to corticosterone $(400 \mu \mathrm{mol} / \mathrm{L})$ significantly elevated the level of xanthine and increased the activity of XOD $(P<0.01, P<0.01)$. In contrast, pretreatment with SSA and SSA and AF combination significantly reversed the phenomenon induced by corticosterone, meanwhile, the effect of the SSA and AF combination was significantly better than SSA (Fig. 6D/E). To verify the effect of SSA on purine metabolism, the XOD inhibitor febuxostat (FBX) was applied. The effect of FBX alone was assessed in PC12 cells. As shown in Fig. 3SA, 1$100 \mathrm{nmol} / \mathrm{L}$ FBX revealed no obvious effects. Therefore, FBX concentrations of 10, 25, 50, and $100 \mathrm{nmol} / \mathrm{L}$ were used to evaluate the effect on corticosterone-induced PC12 cells. As shown in Fig. 3SB, the cell viability was increased in a dose-dependent manner, when treated with 25,50 , and $100 \mathrm{nmol} / \mathrm{L}$ FBX $(P<0.05, P<0.01, P<0.01)$. Moreover, SSA had the same effect as FBX to reduce xanthine levels $(P$ $<0.01, P<0.01)$ and inhibit XOD activity $(P<0.01, P<0.01)$ (Fig. 6D/E). In addition, FBX $(100 \mathrm{nmol} / \mathrm{L})$ enhanced the neuroprotective effect of $\mathrm{AF}(25 \mu \mathrm{mol} / \mathrm{L})$ and SSA and AF combination $(2.5 \mathrm{and} 25 \mu \mathrm{mol} / \mathrm{L})$ $(P<0.05, P<0.05)$ (Fig. 6F). The above results indicated that SSA regulated purine metabolism disorders by inhibiting XOD activity.

\subsection{AF protected corticosterone-induced neuro-injury by regulating glutamate metabolism disorders}

To evaluate the regulation effects of SSA and AF, alone and in combination, on glutamate metabolism, the level of glutamate in cells culture supernatant, and the activity of GLS in cells were detected. Exposure to corticosterone $(400 \mu \mathrm{mol} / \mathrm{L})$ significantly elevated the level of glutamate and increased the activity of glutamate $(P<0.05, P<0.01)$. In contrast, pretreatment with AF and SSA and AF combination significantly reversed the phenomenon induced by corticosterone, meanwhile, the effect of the SSA and AF combination was significantly better than AF (Fig. 6G/H). To verify the effect of AF on glutamate metabolism, the GLS inhibitor BPTES was applied. The effect of BPTES alone was assessed in PC12 cells. As shown in Fig. 3SC, $0.25-25 \mu \mathrm{mol} / \mathrm{L}$ BPTES revealed no obvious effects. Therefore, BPTES concentrations of $0.25,0.5,1$, and $2.5 \mu \mathrm{mol} / \mathrm{L}$ were used to evaluate the effect on corticosterone-induced PC12 cells. As shown in Fig. 3SD, the cell viability was increased in a dose-dependent manner, when treated with 1 , and $2.5 \mu \mathrm{mol} / \mathrm{L}$ BPTES $(\mathrm{P}<0.05, \mathrm{P}<0.01)$. Moreover, AF had the same effect as BPTES to reduce glutamate levels $(P<0.01, P<0.01)$ and inhibit GLS activity $(P<0.01, P<0.01)(F i g .6 G / H)$. In addition, BPTES $(25 \mu \mathrm{mol} / \mathrm{L})$ enhanced the neuroprotective effect of SSA $(2.5 \mu \mathrm{mol} / \mathrm{L})$ and SSA and AF combination $(2.5$ and $25 \mu \mathrm{mol} / \mathrm{L})(\mathrm{P}<0.05, \mathrm{P}<0.05)$ (Fig. $6 \mathrm{l})$. The above results indicated that $A F$ regulated glutamate metabolism disorders by inhibiting GLS activity.

\subsection{SSA and AF protected corticosterone-induced neuro- injury by inhibiting oxidative stress and inhibiting inflammation}


To evaluate the anti-oxidation effect of SSA and AF, alone and in combination, the levels of ROS were detected. Exposure of PC12 cells to corticosterone significantly elevated the level of ROS $(P<0.01)$. In contrast, treatment with SSA and SSA and AF combination significantly reversed the phenomenon induced by corticosterone $(P<0.01, P<0.01)$, meanwhile, the effect of the SSA and AF combination was significantly better than SSA $(P<0.01)(F i g .7 A / B / C / D)$. To evaluate the anti-inflammatory effect of SSA, $A F$, and SSA and AF combination, the level of IL-1 $\beta$, IL-6, and TNF-a were detected. Exposure of PC12 cells to corticosterone significantly elevated the level of IL-1 $\beta(P<0.01)$, IL-6 $(P<0.01)$, and TNF-a $(P<0.01)$. In contrast, pretreatment with SSA, AF, and SSA and $A F$ combination significantly reversed the phenomenon induced by corticosterone $(P<0.01, P<0.01, P<0.01)$, meanwhile, the effect of the SSA and AF combination was significantly better than SSA or AF alone $(P<0.01, P<0.01)$ (Fig. 7D/E/F). To clarify the mechanism of SSA, AF, and SSA and AF combination on anti-inflammatory, the expression of NLRP3 was assessed. Figure $7 \mathrm{G} / \mathrm{H} /$ showed that corticosterone treatment significantly upregulated the expression of NLRP3. However, pre-treatment with SSA, AF, and SSA and AF combination blocked these effects, meanwhile, the effect of the SSA and AF combination was significantly better than SSA or AF alone $(P<$ $0.01, P<0.01)$.

\section{Discussion}

The TCM formulas follow the compatibility principle 'sovereign, minister, assistant, and courier', which means herbs play the primary, secondary, auxiliary, and harmonic roles, respectively, to achieve the optimally holistic effect [18]. Based on TCM theory,Bupleurum chinense DC and Paeonia lactiflora Pall are the "Sovereign" and the "Minister" herb respectively, so that, Paeonia lactiflora Pall can enhance the effect of Bupleurum chinense DC for treating depression in TCM prescriptions [17]. The ancient compatibility principle is based on experiences, but whether its underlying interactions can be explained by modern biotechnology is unknown.

The results of this study showed that SSA and AF synergistically reverse metabolic disorders and protect the neuronal cells' injury induced by corticosterone. This is the first report to demonstrate the underlying synergistic mechanism of SSA and AF counteracting by rescuing the neurons from the pathogenic effect of metabolic disorders. Consistent with the previous studies, high-level corticosterone initiated cell death $[35,36,32]$. Besides, our finding from the cell viability assay infers significant synergism existing between SSA and AF. Several studies ascertain the specific mode of action of SSA and AF promoting neuronal survival, which further supports our finding [37-41]. Interestingly, the present data also show that SSA in combination with AF was able to improve the cell viability through regulation of the metabolic disorders induced by corticosterone.

The data obtained in cell metabolomics suggested that SSA and AF differentially affect several mitochondrial biochemical related pathways. Mitochondria is the most complex and metabolically active organelles in the cell which harboring pathways involved in ATP synthesis through the TCA cycle and oxidative phosphorylation [42]. Furthermore, the mitochondrion is an important apoptotic hub that can regulate apoptosis by releasing cell apoptosis-inducing factors [43]. Studies have shown that impairment 
in the mitochondrial functions leads to the generation of various insults that exaggerate the pathogenesis of depression [44]. Previous studies have shown that corticosterone could induce TCA cycle disturbance in PC12 cells [45]. Consistent with this, our experiment confirmed that phenomena and also observed the mitochondrial function impaired. The results showed that SSA and AF could regulate the metabolic disorder induced by corticosterone, which was achieved by improving mitochondrial function.

Metabolic disorders of purine metabolism affecting the nervous system [46]. Purine metabolism is also implicated in the pathogenesis of depression [47]. XOD is known to generate oxidative stress through ROS production by catalyzing the hypoxanthine $\rightarrow$ xanthine $\rightarrow$ urate synthesis [48]. In our study, corticosterone induced the perturbation of purine metabolism by elevating the level of xanthine and increased the activity of XOD in PC12 cells. And SSA could reverse this phenomenon by inhibiting the activity of XOD. This indicated that SSA could regulate purine metabolic disorders induced by corticosterone. Moreover, consistent with previous studies, we confirmed that corticosterone could increase the level of ROS in PC12 cells. However, SSA could reverse this phenomenon by inhibiting the activity of XOD.

XOD-produced ROS can increase the synthesis of pro-IL-1 $\beta$, which provides one necessary signal for the activation of the NLRP3 inflammasome [49]. Inflammation and oxidative stress are related to the pathogenesis of depression [50]. Consistent with this, our experiment observed that corticosterone could induce inflammation in PC12 cells, and SSA and AF could reverse this phenomenon by inhibiting the expression of NLRP3. And, glutamate metabolism could be disrupted by inflammation [51]. The effects of inflammation on glia initially lead to an increased release of glutamate into the extrasynaptic space. This glutamate can activate extrasynaptic $\mathrm{N}$-methyl-d-aspartate (NMDA) receptors and lead to loss of synaptic integrity, ultimately resulting in neuronal loss, eventually lead to depression [52]. Our results indicated that corticosterone-induced glutamate metabolism disorders and treatment with AF could regulate it by inhibiting the activity of GLS.

\section{Conclusions}

Collectively, the present study elucidated how SSA and AF synergistically were able to regulate metabolic disorders and protect the neuronal cells from corticosterone damage (Figure 8). This study provided that SSA in combination with AF may represent a promising combination therapeutic strategy for the treatment of depression.

\section{Declarations}

Author Contributions $\mathrm{XL}, \mathrm{YZ}, \mathrm{XQ}$, and $\mathrm{XW}$ conceived and designed the experiment. $\mathrm{XL}, \mathrm{HS}$, and $\mathrm{YZ}$ performed the experiments. $\mathrm{XL}, \mathrm{YW}, \mathrm{RH}, \mathrm{JT}, \mathrm{XG}$, and $\mathrm{GD}$ analyzed the data. $\mathrm{XL}, \mathrm{XQ}$, and $\mathrm{YZ}$ wrote the paper. 
Funding Statement This study was funded by the National Nature Science Foundation of China (No. 81673572, No. 82074323), the major science and technology project for "Significant New Drugs Creation" (No. 2017ZX09301047). Research Project Supported by the Shanxi Scholarship Council of China (No. 2020019). Overseas returning scholar science and technology activities merit-funded project (No. 201991).

\section{Availability of data and material Not applicable}

Compliance with ethical standards Not applicable

Consent to participate Not applicable

Consent for Publication Not applicable

Conflict of interest The authors declare that they have no conflict of interest.

\section{References}

1. Whiteford HA, Degenhardt L, Rehm J, Baxter AJ, Ferrari AJ, Erskine HE, Charlson FJ, Norman RE, Flaxman AD, Johns N, Burstein R, Murray CJL, Vos T (2013) Global burden of disease attributable to mental and substance use disorders: findings from the Global Burden of Disease Study 2010. The Lancet 382 (9904):1575-1586. doi:https://doi.org/10.1016/S0140-6736(13)61611-6

2. Puri BK, Counsell SJ, Richardson AJ, Horrobin DF (2002) Eicosapentaenoic acid in treatmentresistant depression. Archives of general psychiatry 59 (1):91-92. doi:10.1001/archpsyc.59.1.91-a

3. Hughes S, Lacasse J, Fuller RR, Spaulding-Givens J (2017) Adverse effects and treatment satisfaction among online users of four antidepressants. Psychiatry research 255:78-86. doi:10.1016/j.psychres.2017.05.021

4. Read J, Gee A, Diggle J, Butler H (2017) The interpersonal adverse effects reported by 1008 users of antidepressants; and the incremental impact of polypharmacy. Psychiatry research 256:423-427. doi:10.1016/j.psychres.2017.07.003

5. Dodd S, Mitchell PB, Bauer M, Yatham L, Young AH, Kennedy SH, Williams L, Suppes T, Lopez Jaramillo C, Trivedi MH, Fava M, Rush AJ, Mclntyre RS, Thase ME, Lam RW, Severus E, Kasper S, Berk $M$ (2018) Monitoring for antidepressant-associated adverse events in the treatment of patients with major depressive disorder: An international consensus statement. The world journal of biological psychiatry : the official journal of the World Federation of Societies of Biological Psychiatry 19 (5):330-348. doi:10.1080/15622975.2017.1379609

6. Yang F, Dong X, Yin X, Wang W, You L, Ni J (2017) Radix Bupleuri: A Review of Traditional Uses, Botany, Phytochemistry, Pharmacology, and Toxicology. BioMed research international 2017:7597596. doi:10.1155/2017/7597596

7. Li X, Li X, Huang N, Liu R, Sun R (2018) A comprehensive review and perspectives on pharmacology and toxicology of saikosaponins. Phytomedicine : international journal of phytotherapy and 
phytopharmacology 50:73-87. doi:https://doi.org/10.1016/j.phymed.2018.09.174

8. Chen X-Q, Chen S-J, Liang W-N, Wang M, Li C-F, Wang S-S, Dong S-Q, Yi L-T, Li C-D (2018) Saikosaponin A attenuates perimenopausal depression-like symptoms by chronic unpredictable mild stress. Neuroscience letters 662:283-289. doi:https://doi.org/10.1016/j.neulet.2017.09.046

9. Guo J, Zhang F, Gao J, Guan X, Liu B, Wang X, Qin Z, Tang K, Liu S (2020) Proteomics-based screening of the target proteins associated with antidepressant-like effect and mechanism of Saikosaponin A. J Cell Mol Med 24 (1):174-188. doi:10.1111/jcmm.14695

10. Mao X, Miao G, Tao X, Hao S, Zhang H, Li H, Hou Z, Tian R, Lu T, Ma J, Zhang X, Cheng H, Liu B (2016) Saikosaponin a protects TBI rats after controlled cortical impact and the underlying mechanism. Am J Transl Res 8 (1):133-141

11. Mao Q, Huang Z, Ip S, Che C (2008) Antidepressant-like effect of ethanol extract from Paeonia lactiflora in mice. 22 (11):1496-1499. doi:10.1002/ptr.2519

12. Ma X, Wen J-X, Gao S-J, He X, Li P-Y, Yang Y-X, Wei S-Z, Zhao Y-L, Xiao X-H (2018) Paeonia lactiflora Pall. regulates the NF-KB-NLRP3 inflammasome pathway to alleviate cholestasis in rats. 70 (12):1675-1687. doi:10.1111/jphp.13008

13. Zhao Z-X, Fu J, Ma S-R, Peng R, Yu J-B, Cong L, Pan L-B, Zhang Z-G, Tian H, Che C-T, Wang Y, Jiang JD (2018) Gut-brain axis metabolic pathway regulates antidepressant efficacy of albiflorin. Theranostics 8 (21):5945-5959. doi:10.7150/thno.28068

14. See-Lok H, Chung-Yan P, Chengyuan L, Ting Y, Daniel Wai-Jing K, Ken Kin-Lam Y, Man SW, Zhaoxiang $B$, Hung-Wing $L$ (2015) Inhibition of $\beta$-Amyloid Aggregation by Albiflorin, Aloeemodin and Neohesperidin and their Neuroprotective Effect on Primary Hippocampal Cells Against $\beta$-Amyloid Induced Toxicity. Current Alzheimer Research 12 (5):424-433. doi:http://dx.doi.org/10.2174/1567205012666150504144919

15. Zhu HZ, Liang YD, Ma QY, Hao WZ, Li XJ, Wu MS, Deng LJ, Li YM, Chen JX (2019) Xiaoyaosan improves depressive-like behavior in rats with chronic immobilization stress through modulation of the gut microbiota. Biomedicine \& pharmacotherapy = Biomedecine \& pharmacotherapie 112:108621. doi:10.1016/j.biopha.2019.108621

16. Zhou J, Cai H, Tu S, Duan Y, Pei K, Xu Y, Liu J, Niu M, Zhang Y, Shen L, Zhou Q (2018) Identification and Analysis of Compound Profiles of Sinisan Based on 'Individual Herb, Herb-Pair, Herbal Formula' before and after Processing Using UHPLC-Q-TOF/MS Coupled with Multiple Statistical Strategy. Molecules (Basel, Switzerland) 23 (12). doi:10.3390/molecules23123128

17. Zhou J, Cai H, Duan Y, Pei K, Fan KL, Xu YY, Zhao JY, Liu J (2018) [Research progress on antidepressant effects of Sini San based on three progressive levels of "single herb, herb-pair, and complicated Chinese herbal formula"]. Zhongguo Zhong yao za zhi = Zhongguo zhongyao zazhi = China journal of Chinese materia medica 43 (1):46-51. doi:10.19540/j.cnki.cjcmm.20171106.014

18. Oh C (2013) A Single Medicine for a Disease: Simple Formula of Treasured Mirror of Eastern Medicine, It's Compilation and Succession. Ui sahak 22 (1):1-40. doi:10.13081/kjmh.2013.22.1 
19. Wang Y, Gao SM, Li R, Zhang M, Gao S, Yu CQ (2016) Antidepressant-like effects of the Radix Bupleuri and Radix Paeoniae Alba drug pair. Neuroscience letters 633:14-20. doi:10.1016/j.neulet.2016.09.001

20. Sun X, Li X, Pan R, Xu Y, Wang Q, Song M (2018) Total Saikosaponins of Bupleurum yinchowense reduces depressive, anxiety-like behavior and increases synaptic proteins expression in chronic corticosterine-treated mice. BMC complementary and alternative medicine 18 (1):117. doi:10.1186/s12906-018-2186-9

21. Liu SC, Hu WY, Zhang WY, Yang L, Li Y, Xiao ZC, Zhang M, He ZY (2019) Paeoniflorin attenuates impairment of spatial learning and hippocampal long-term potentiation in mice subjected to chronic unpredictable mild stress. Psychopharmacology. doi:10.1007/s00213-019-05257-5

22. Li X, Qin XM, Tian JS, Gao XX, Du GH, Zhou YZ (2021) Integrated network pharmacology and metabolomics to dissect the combination mechanisms of Bupleurum chinense DC-Paeonia lactiflora Pall herb pair for treating depression. Journal of ethnopharmacology 264:113281. doi:10.1016/j.jep.2020.113281

23. Johnson $\mathrm{CH}$, Ivanisevic J, Siuzdak G (2016) Metabolomics: beyond biomarkers and towards mechanisms. Nature reviews Molecular cell biology 17 (7):451-459. doi:10.1038/nrm.2016.25

24. Yang D, Wu W, Gan G, Wang D, Gong J, Fang K, Lu F (2020) (-)-Syringaresinol-4-O- $\beta-D-$ glucopyranoside from Cortex Albizziae inhibits corticosterone-induced PC12 cell apoptosis and relieves the associated dysfunction. Food and Chemical Toxicology 141:111394. doi:https://doi.org/10.1016/j.fct.2020.111394

25. Yin C-I, Lu R-g, Zhu J-f, Huang H-m, Liu X, Li Q-f, Mo Y-y, Zhu H-j, Chin B, Wu J-x, Liu X-w, Cheng B, Ruan J-x, Liang Y-h, Song H, Guo H-w, Su Z-h, Zheng H (2019) The study of neuroprotective effect of ferulic acid based on cell metabolomics. European journal of pharmacology 864:172694. doi:https://doi.org/10.1016/j.ejphar.2019.172694

26. Tian J-s, Liu S-b, He X-y, Xiang H, Chen J-I, Gao Y, Zhou Y-z, Qin X-m (2018) Metabolomics studies on corticosterone-induced PC12 cells: A strategy for evaluating an in vitro depression model and revealing the metabolic regulation mechanism. Neurotoxicology and Teratology 69:27-38. doi:https://doi.org/10.1016/j.ntt.2018.07.002

27. Gao L, Zhou F, Wang K-x, Zhou Y-z, Du G-h, Qin X-m (2020) Baicalein protects PC12 cells from Aß2535-induced cytotoxicity via inhibition of apoptosis and metabolic disorders. Life sciences 248:117471. doi:https://doi.org/10.1016/j.Ifs.2020.117471

28. Faccio AT, Ruperez FJ, Singh NS, Angulo S, Tavares MFM, Bernier M, Barbas C, Wainer IW (2018) Stereochemical and structural effects of (2R,6R)-hydroxynorketamine on the mitochondrial metabolome in PC-12 cells. Biochimica et Biophysica Acta (BBA) - General Subjects 1862 (6):15051515. doi:https://doi.org/10.1016/j.bbagen.2018.03.008

29. Yuan H, Ma Q, Cui H, Liu G, Zhao X, Li W, Piao G (2017) How Can Synergism of Traditional Medicines Benefit from Network Pharmacology? Molecules (Basel, Switzerland) 22 (7):1135. doi:10.3390/molecules22071135 
30. Zhang N, Fu JN, Chou TC (2016) Synergistic combination of microtubule targeting anticancer fludelone with cytoprotective panaxytriol derived from panax ginseng against MX-1 cells in vitro: experimental design and data analysis using the combination index method. American journal of cancer research 6 (1):97-104

31. Di Veroli GY, Fornari C, Wang D, Mollard S, Bramhall JL, Richards FM, Jodrell DI (2016) Combenefit: an interactive platform for the analysis and visualization of drug combinations. Bioinformatics (Oxford, England) 32 (18):2866-2868. doi:10.1093/bioinformatics/btw230

32. Li X, Qin X, Tian J, Gao X, Wu X, Du G, Zhou Y (2020) Liquiritin protects PC12 cells from corticosterone-induced neurotoxicity via regulation of metabolic disorders, attenuation ERK1/2-NF-KB pathway, activation Nrf2-Keap1 pathway, and inhibition mitochondrial apoptosis pathway. Food and chemical toxicology : an international journal published for the British Industrial Biological Research Association 146:111801. doi:10.1016/j.fct.2020.111801

33. Gross C, Seroogy KB (2020) Chapter 6 - Neuroprotective roles of neurotrophic factors in depression. In: Gozes I, Levine J (eds) Neuroprotection in Autism, Schizophrenia and Alzheimer's Disease. Academic Press, pp 125-144. doi:https://doi.org/10.1016/B978-0-12-814037-6.00007-0

34. Faccio AT, Ruperez FJ, Singh NS, Angulo S, Tavares MFM, Bernier M, Barbas C, Wainer IW (2018) Stereochemical and structural effects of (2R,6R)-hydroxynorketamine on the mitochondrial metabolome in PC-12 cells. Biochimica et biophysica acta General subjects 1862 (6):1505-1515. doi:10.1016/j.bbagen.2018.03.008

35. Zeng Z, Wang X, Bhardwaj SK, Zhou X, Little PJ, Quirion R, Srivastava LK, Zheng W (2017) The Atypical Antipsychotic Agent, Clozapine, Protects Against Corticosterone-Induced Death of PC12 Cells by Regulating the Akt/FoxO3a Signaling Pathway. Molecular neurobiology 54 (5):3395-3406. doi:10.1007/s12035-016-9904-4

36. Xiao X, Shang X, Zhai B, Zhang H, Zhang T (2018) Nicotine alleviates chronic stress-induced anxiety and depressive-like behavior and hippocampal neuropathology via regulating autophagy signaling. Neurochemistry international 114:58-70. doi:10.1016/j.neuint.2018.01.004

37. Mao X, Miao G, Tao X, Hao S, Zhang H, Li H, Hou Z, Tian R, Lu T, Ma J, Zhang X, Cheng H, Liu B (2016) Saikosaponin a protects TBI rats after controlled cortical impact and the underlying mechanism. American journal of translational research 8 (1):133-141

38. Li ZY, Guo Z, Liu YM, Liu XM, Chang Q, Liao YH, Pan RL (2013) Neuroprotective effects of total saikosaponins of Bupleurum yinchowense on corticosterone-induced apoptosis in PC12 cells. Journal of ethnopharmacology 148 (3):794-803. doi:10.1016/j.jep.2013.04.057

39. Ye M, Bi YF, Ding L, Zhu WW, Gao W (2016) Saikosaponin a functions as anti-epileptic effect in pentylenetetrazol induced rats through inhibiting mTOR signaling pathway. Biomedicine \& pharmacotherapy $=$ Biomedecine \& pharmacotherapie 81:281-287.

doi:10.1016/j.biopha.2016.04.012

40. Ho SL, Poon CY, Lin C, Yan T, Kwong DW, Yung KK, Wong MS, Bian Z, Li HW (2015) Inhibition of $\beta$ amyloid Aggregation By Albiflorin, Aloeemodin And Neohesperidin And Their Neuroprotective Effect 
On Primary Hippocampal Cells Against $\beta$-amyloid Induced Toxicity. Current Alzheimer research 12 (5):424-433. doi:10.2174/1567205012666150504144919

41. Wang D, Tan QR, Zhang ZJ (2013) Neuroprotective effects of paeoniflorin, but not the isomer albiflorin, are associated with the suppression of intracellular calcium and calcium/calmodulin protein kinase II in PC12 cells. Journal of molecular neuroscience : MN 51 (2):581-590. doi:10.1007/s12031-013-0031-7

42. van der Bliek AM, Sedensky MM, Morgan PG (2017) Cell Biology of the Mitochondrion. Genetics 207 (3):843-871. doi:10.1534/genetics.117.300262

43. Estaquier J, Vallette F, Vayssiere JL, Mignotte B (2012) The mitochondrial pathways of apoptosis. Advances in experimental medicine and biology 942:157-183. doi:10.1007/978-94-007-2869-1_7

44. Bansal Y, Kuhad A (2016) Mitochondrial Dysfunction in Depression. Current neuropharmacology 14 (6):610-618. doi:10.2174/1570159x14666160229114755

45. Yin CL, Lu RG, Zhu JF, Huang HM, Liu X, Li QF, Mo YY, Zhu HJ, Chin B, Wu JX, Liu XW, Cheng B, Ruan JX, Liang YH, Song H, Guo HW, Su ZH, Zheng H (2019) The study of neuroprotective effect of ferulic acid based on cell metabolomics. European journal of pharmacology 864:172694. doi:10.1016/j.ejphar.2019.172694

46. Jinnah HA, Sabina RL, Van Den Berghe G (2013) Metabolic disorders of purine metabolism affecting the nervous system. Handb Clin Neurol 113:1827-1836. doi:10.1016/B978-0-444-59565-2.00052-6

47. Park DI, Dournes C, Sillaber I, Uhr M, Asara JM, Gassen NC, Rein T, Ising M, Webhofer C, Filiou MD, Müller MB, Turck CW (2016) Purine and pyrimidine metabolism: Convergent evidence on chronic antidepressant treatment response in mice and humans. Scientific reports 6:35317-35317. doi:10.1038/srep35317

48. George J, Struthers AD (2009) Role of urate, xanthine oxidase and the effects of allopurinol in vascular oxidative stress. Vasc Health Risk Manag 5 (1):265-272. doi:10.2147/vhrm.s4265

49. Ty MC, Zuniga M, Götz A, Kayal S, Sahu PK, Mohanty A, Mohanty S, Wassmer SC, Rodriguez A (2019) Malaria inflammation by xanthine oxidase-produced reactive oxygen species. EMBO Mol Med 11 (8):e9903-e9903. doi:10.15252/emmm.201809903

50. Lindqvist D, Dhabhar FS, James SJ, Hough CM, Jain FA, Bersani FS, Reus VI, Verhoeven JE, Epel ES, Mahan L, Rosser R, Wolkowitz OM, Mellon SH (2017) Oxidative stress, inflammation and treatment response in major depression. Psychoneuroendocrinology 76:197-205. doi:10.1016/j.psyneuen.2016.11.031

51. Haroon E, Miller AH (2017) Inflammation Effects on Brain Glutamate in Depression: Mechanistic Considerations and Treatment Implications. Current topics in behavioral neurosciences 31:173-198. doi:10.1007/7854_2016_40

52. Haroon E, Miller AH, Sanacora G (2017) Inflammation, Glutamate, and Glia: A Trio of Trouble in Mood Disorders. Neuropsychopharmacology : official publication of the American College of Neuropsychopharmacology 42 (1):193-215. doi:10.1038/npp.2016.199 

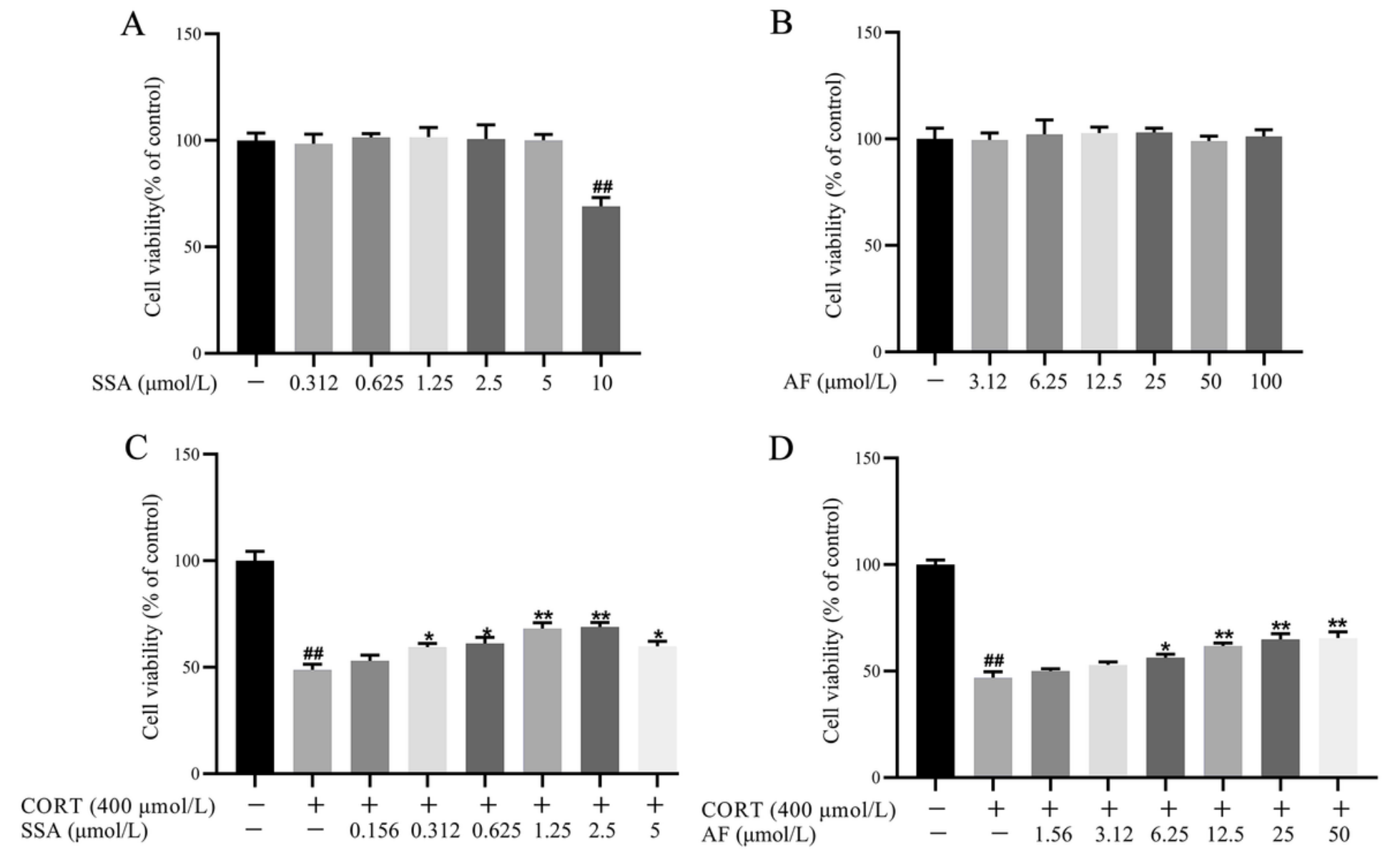

\section{Figure 1}

The neuroprotection effect of SSA and AF. (A/B) Effect of SSA and AF alone on PC12 cells. (C/D) The neuroprotection effect of SSA and AF on corticosterone-induced injury in PC12 cells. Data are expressed as a percentage of control and the results were expressed as the means $\pm S D, n=6$. \#\#P $<0.01$ vs control group; ${ }^{*} \mathrm{P}<0.05$ and ${ }^{* *} \mathrm{P}<0.01$ vs corticosterone group. CORT: corticosterone, SSA: saikosaponin A, AF: albiflorin. 

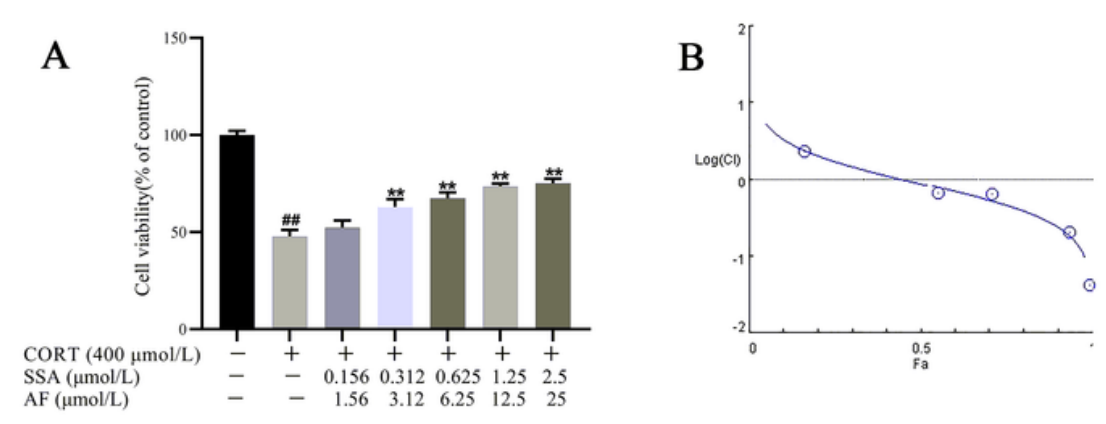

$\odot$ SF

$\mathrm{C}$

D

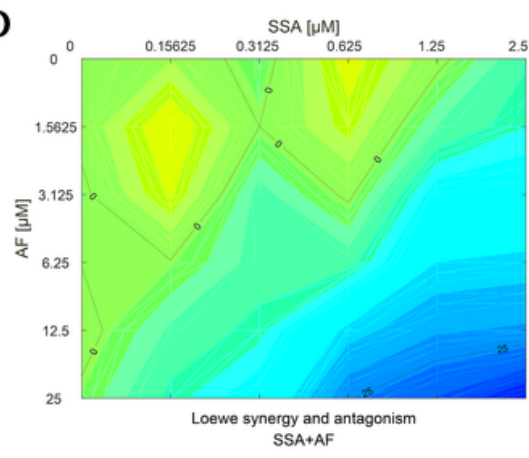

G

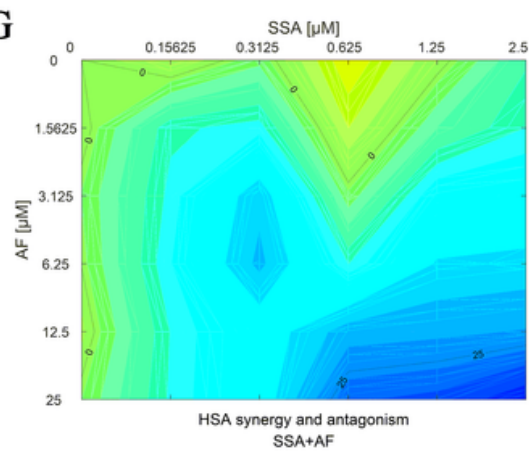

$\mathrm{E}$

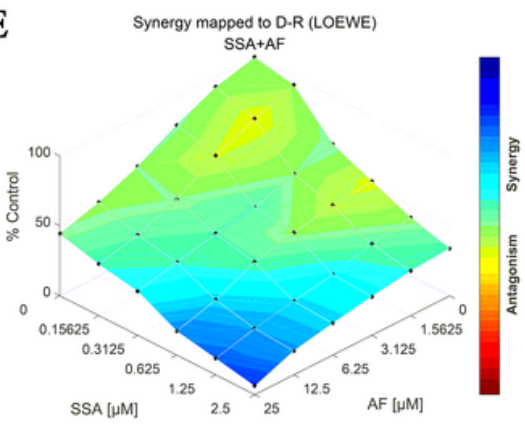

$\mathrm{H}$

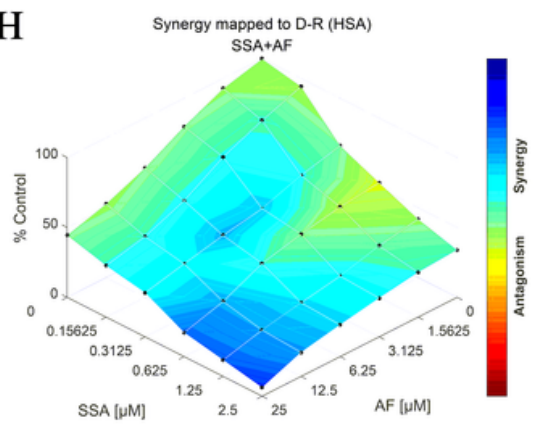

\begin{tabular}{|c|c|c|c|c|}
\hline $\begin{array}{c}\text { SSA Dose } \\
(\mu \mathrm{mol} / \mathrm{L})\end{array}$ & $\begin{array}{c}\text { AF Dose } \\
(\boldsymbol{\mu m o l / L})\end{array}$ & $\begin{array}{c}\text { Total Dose } \\
(\mu \mathrm{mol} / \mathrm{L})\end{array}$ & Fa & CI Value \\
\hline 0.156 & 1.56 & 1.719 & 0.161 & 2.327 \\
0.312 & 3.12 & 3.438 & 0.549 & 0.667 \\
0.625 & 6.25 & 6.875 & 0.708 & 0.644 \\
1.25 & 12.5 & 13.750 & 0.934 & 0.202 \\
\hline 2.5 & 25 & 27.500 & 0.992 & 0.043 \\
\hline
\end{tabular}

$\mathrm{F}$

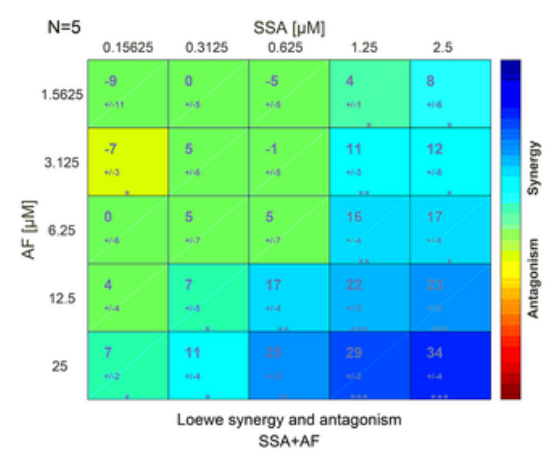

I

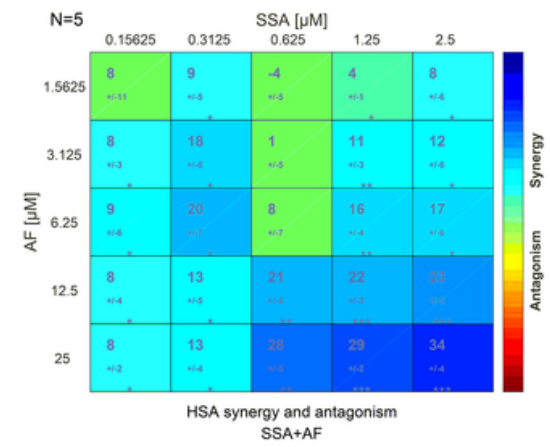

\section{Figure 2}

The synergistic neuroprotection effect of SSA and AF. (A/B/C) Synergy analysis based on Chou-Talalay model $(\mathrm{Cl}<1.0,=1.0$, and $>1.0$, indicating synergistic, additive, and antagonistic effect, respectively). (D/E/F) Synergy analysis based on the Loewe model. (G/H/I) Synergy analysis based on the HAS model (Red surface area indicates antagonism effect and blue surface area indicates synergy). Data are expressed as a percentage of control and the results were expressed as the means $\pm S D, n=6$. \#\#P $<0.01$ vs control group, ${ }^{\star \star} \mathrm{P}<0.01$ vs corticosterone group. CORT: corticosterone, SSA: saikosaponin A, AF: albiflorin. 


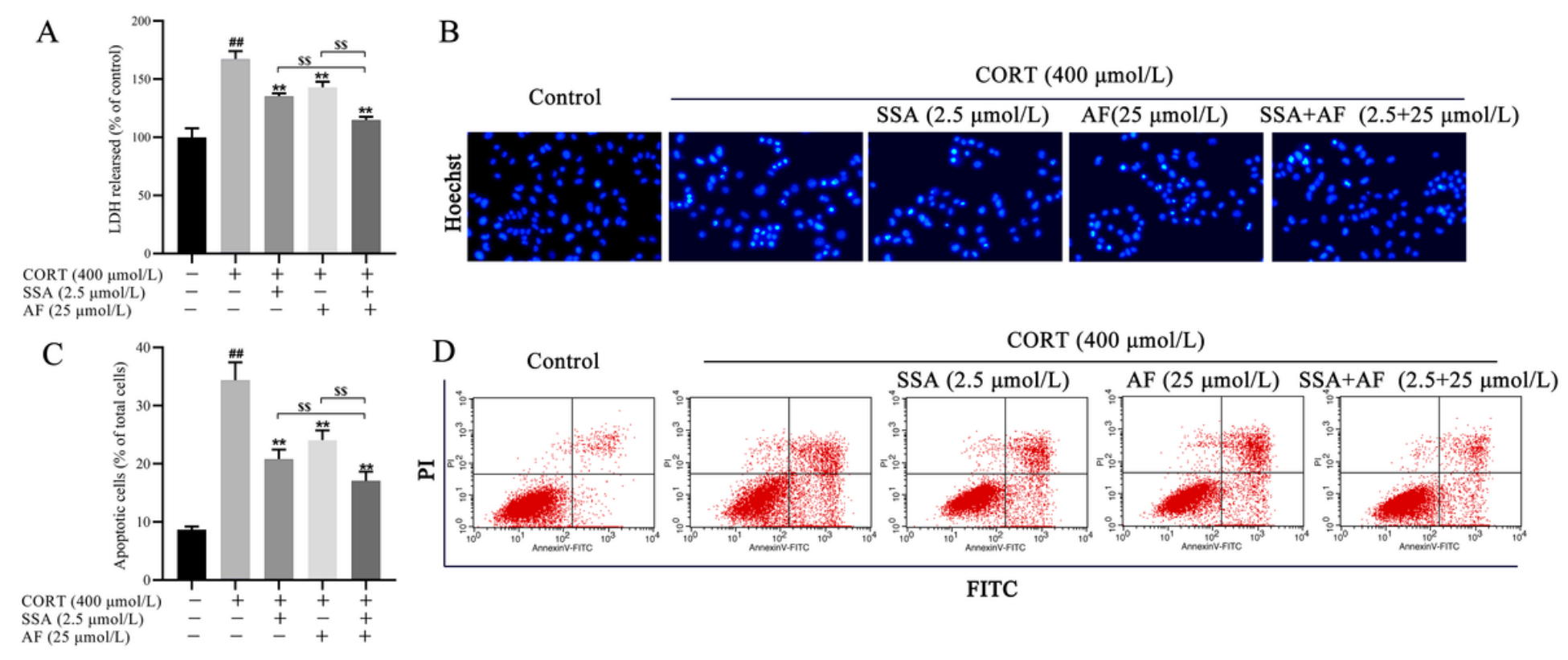

\section{Figure 3}

The neuroprotection effects of SSA and AF. (A) Effects of SSA and AF on LDH leakage in corticosteroneinduced injury PC12 cells ( $n=6)$. (B) Hoechst33342/PI staining assay. Representative images of Hoechstpositive cells (high blue, apoptosis cells). (C/D) Annexin V-FITC/PI flow cytometry assay $(n=3)$. The lower left quadrant (absence of both markers) indicates viable cells; the upper left quadrant (Annexin V-/PI+) indicated cellular necrosis; the upper right quadrant (Annexin V+/PI+) indicates late-stage apoptosis; the lower right quadrant (Annexin $\mathrm{V}+/ \mathrm{PI}$ ) indicates early-stage apoptosis. Early-stage apoptosis and latestage apoptosis were analyzed $(n=3)$. Data are expressed as a percentage of control and the results were expressed as the means $\pm S D, n=6$. \#\#P< 0.01 vs control group; $* * P<0.01$ vs corticosterone group; $\$ \$ P<$ 0.01 vs SSA and AF combination group. CORT: corticosterone, SSA: saikosaponin A, AF: albiflorin. 

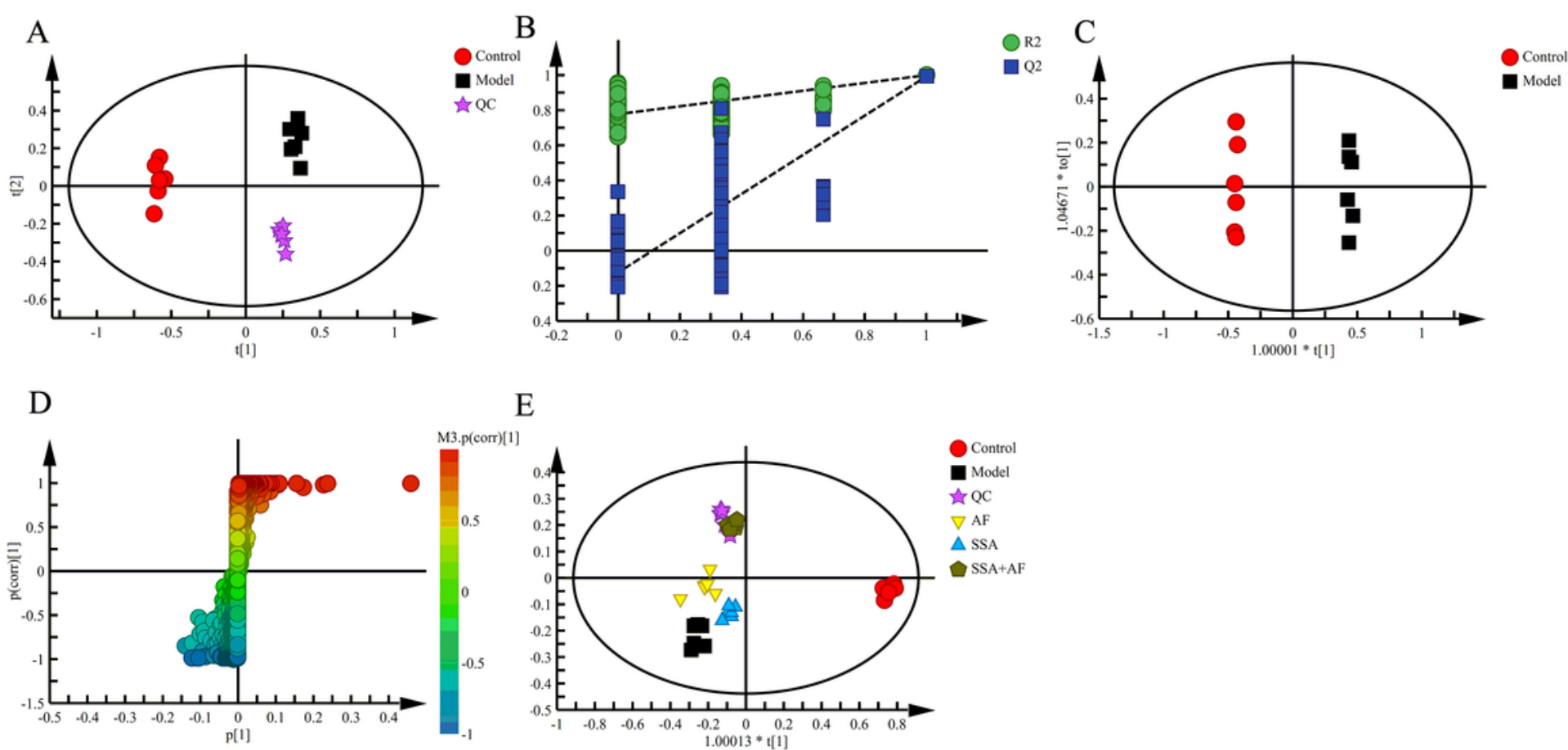

$\mathrm{E}$
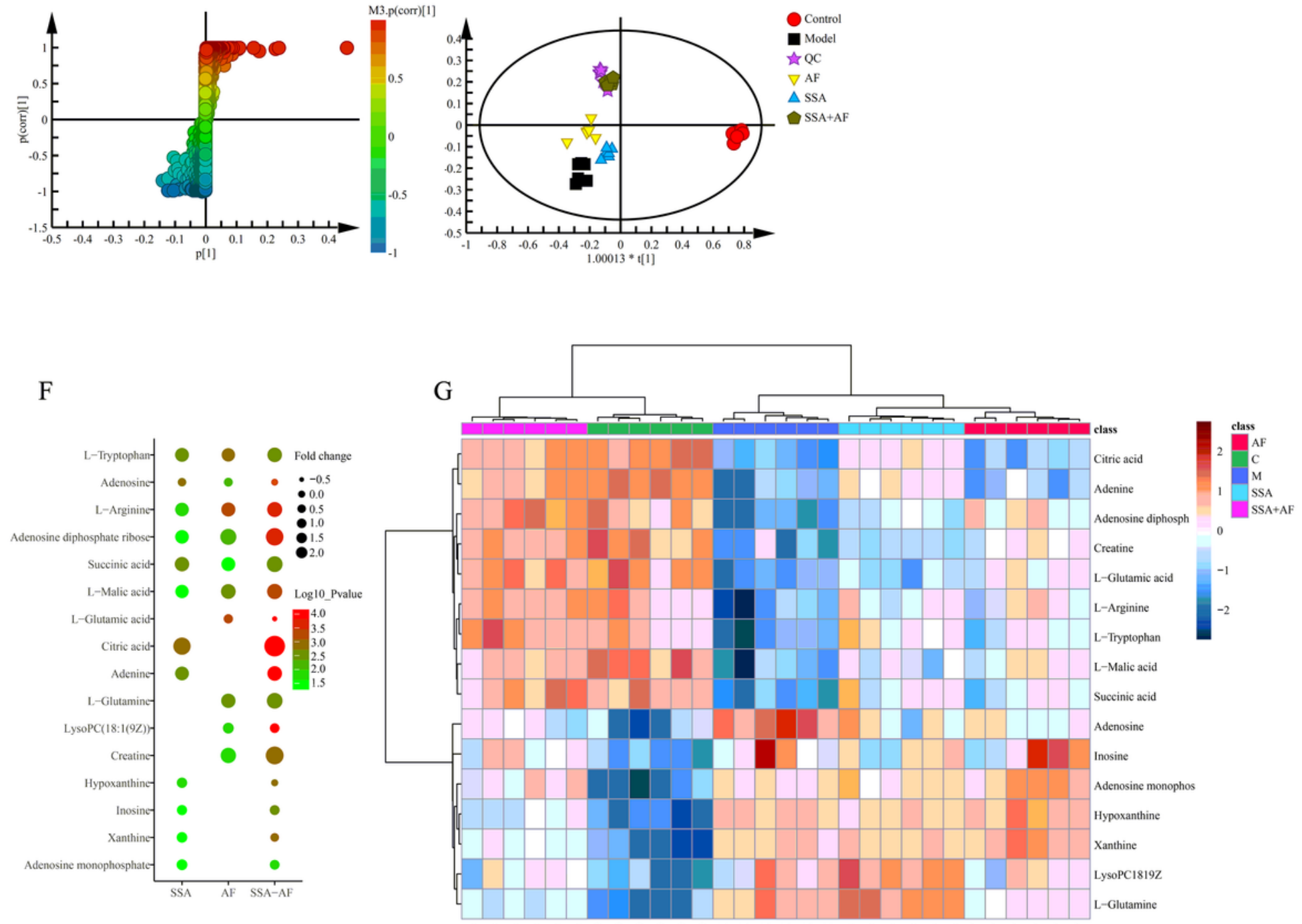

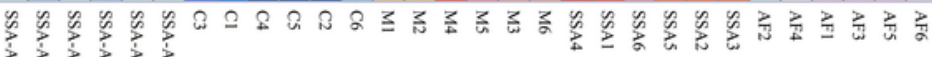

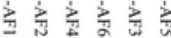

\section{Figure 4}

Effects of SSA and AF on corticosterone-induced metabolic disorders. (A) PCA score plots. (B) PLS-DA model validation diagram. (C) OPLS-DA score plots. (D) S-plot of OPLS-DA. (E) OPLS-DA score plots of plasma samples were collected from different groups. (F) Enrichment map of differential metabolites $(n=6)$. (G) Hierarchical clustering analysis heatmap of differential metabolites in the cells. Brown and blue represent that the levels of differential metabolites are higher and lower compared to the average 
level, respectively. Rows imply the differential metabolites and columns represent cell samples $(n=6)$. SSA: saikosaponin; AF: albiflorin; SSA and AF combination: saikosaponin and albiflorin combination; Model: corticosterone; QC: quality control.

A

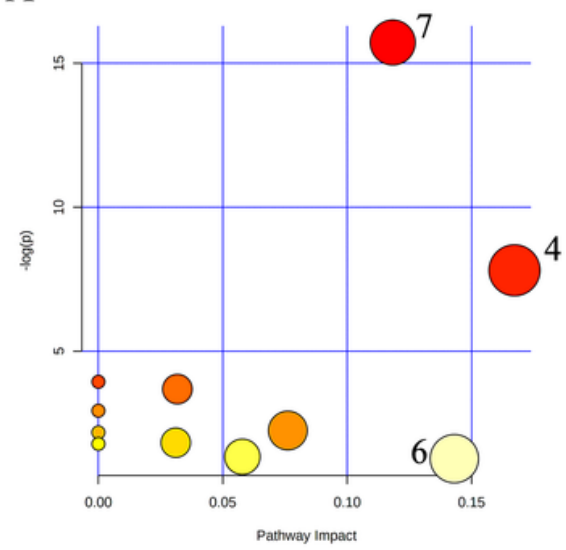

D

\begin{tabular}{|c|c|c|}
\hline Group & $\begin{array}{r}\text { Pathways } \\
\end{array}$ & $\begin{array}{l}\text { Number of } \\
\text { metabolites }\end{array}$ \\
\hline \multirow{3}{*}{ SSA } & 4. Citrate cycle (TCA cycle) & 3 \\
\hline & 6. Tryptophan metabolism & 1 \\
\hline & 7. Purine metabolism & 7 \\
\hline \multirow{5}{*}{ AF } & 1. D-Glutamine and D-glutamate metabolism & 2 \\
\hline & 2. Alanine, aspartate and glutamate metabolism & 3 \\
\hline & 3. Arginine biosynthesis & 3 \\
\hline & 5. Arginine and proline metabolism & 3 \\
\hline & 6. Tryptophan metabolism & 1 \\
\hline \multirow{7}{*}{ SSA-AF } & 1. D-Glutamine and D-glutamate metabolism & 2 \\
\hline & 2. Alanine, aspartate and glutamate metabolism & 4 \\
\hline & 3. Arginine biosynthesis & 3 \\
\hline & 4. Citrate cycle (TCA cycle) & 3 \\
\hline & 5. Arginine and proline metabolism & 3 \\
\hline & 6. Tryptophan metabolism & 1 \\
\hline & 7. Purine metabolism & 8 \\
\hline
\end{tabular}

\section{E}

B

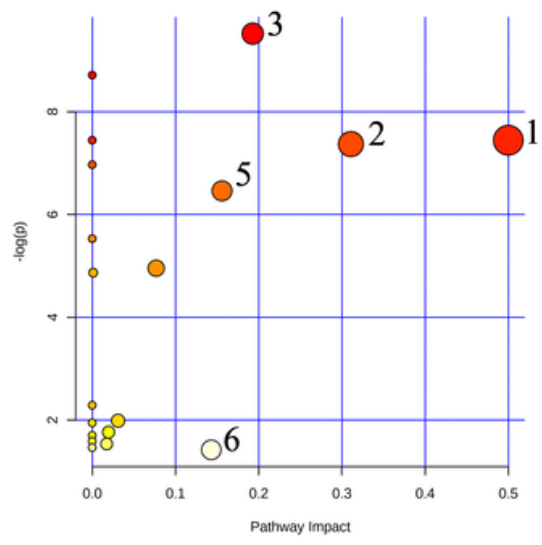

$\mathrm{C}$

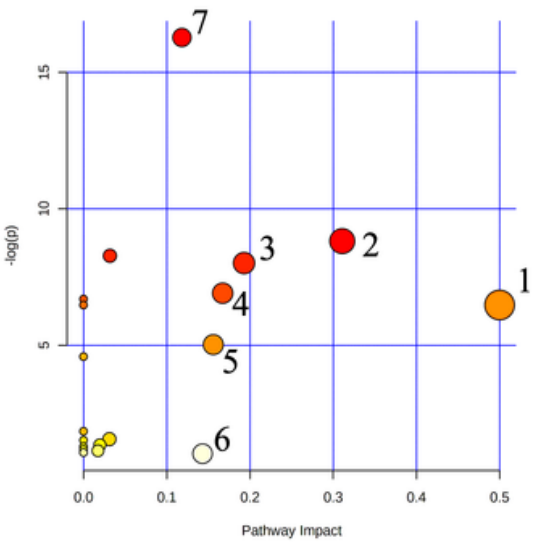

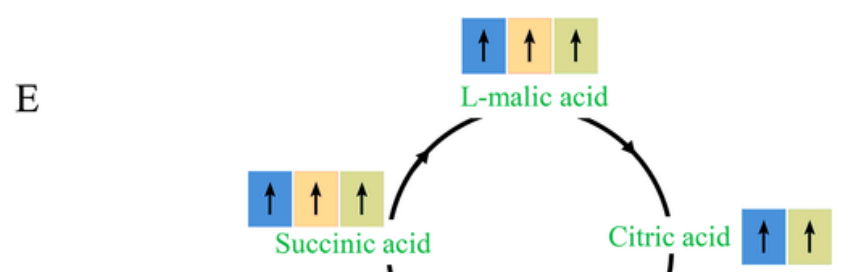

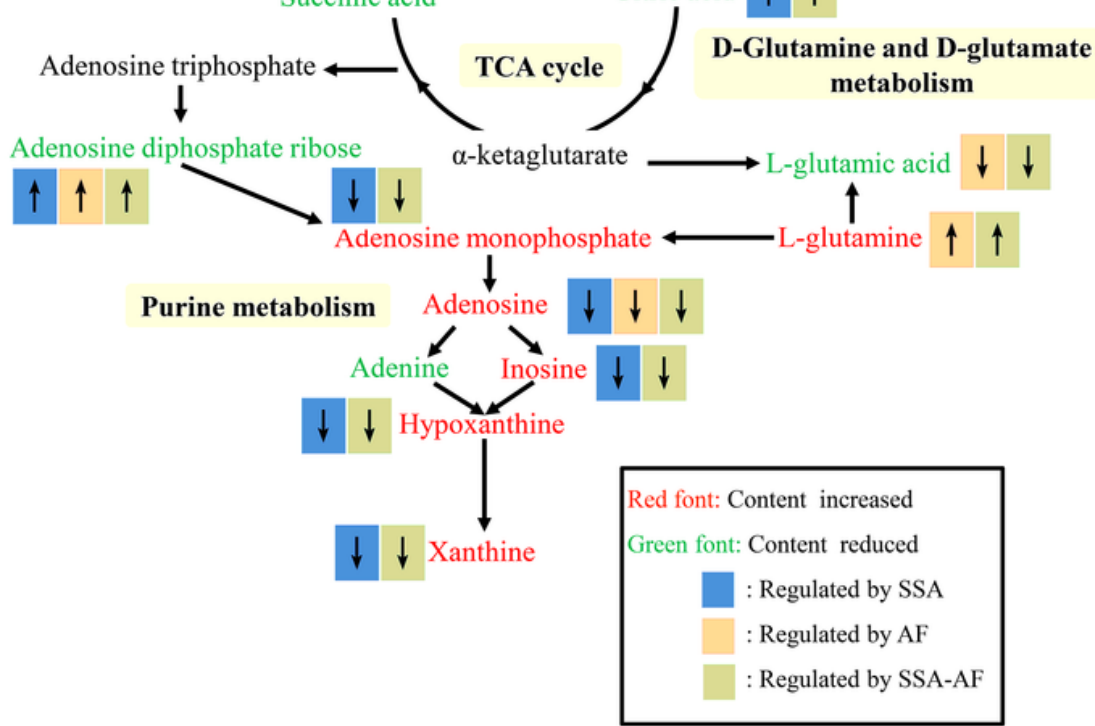

\section{Figure 5}

Effect of SSA and AF on corticosterone-induced metabolic disorders. (A) Metabolic pathway analysis of SSA group. (B) Metabolic pathway analysis of AF group. (C) Metabolic pathway analysis of SSA and AF combination group. (D) Metabolic pathway analysis. (E) Effect of SSA-AF on purine metabolism, glutamate metabolism, and TCA cycle. 1: D-Glutamine and D-glutamate metabolism; 2: Alanine, aspartate, and glutamate metabolism; 3: Arginine biosynthesis; 4: Citrate cycle (TCA cycle); 5: Arginine and proline metabolism; 6: Tryptophan metabolism; 7: Purine metabolism. SSA: saikosaponin; AF: albiflorin; SSA and AF combination: saikosaponin and albiflorin combination; Model: corticosterone. 


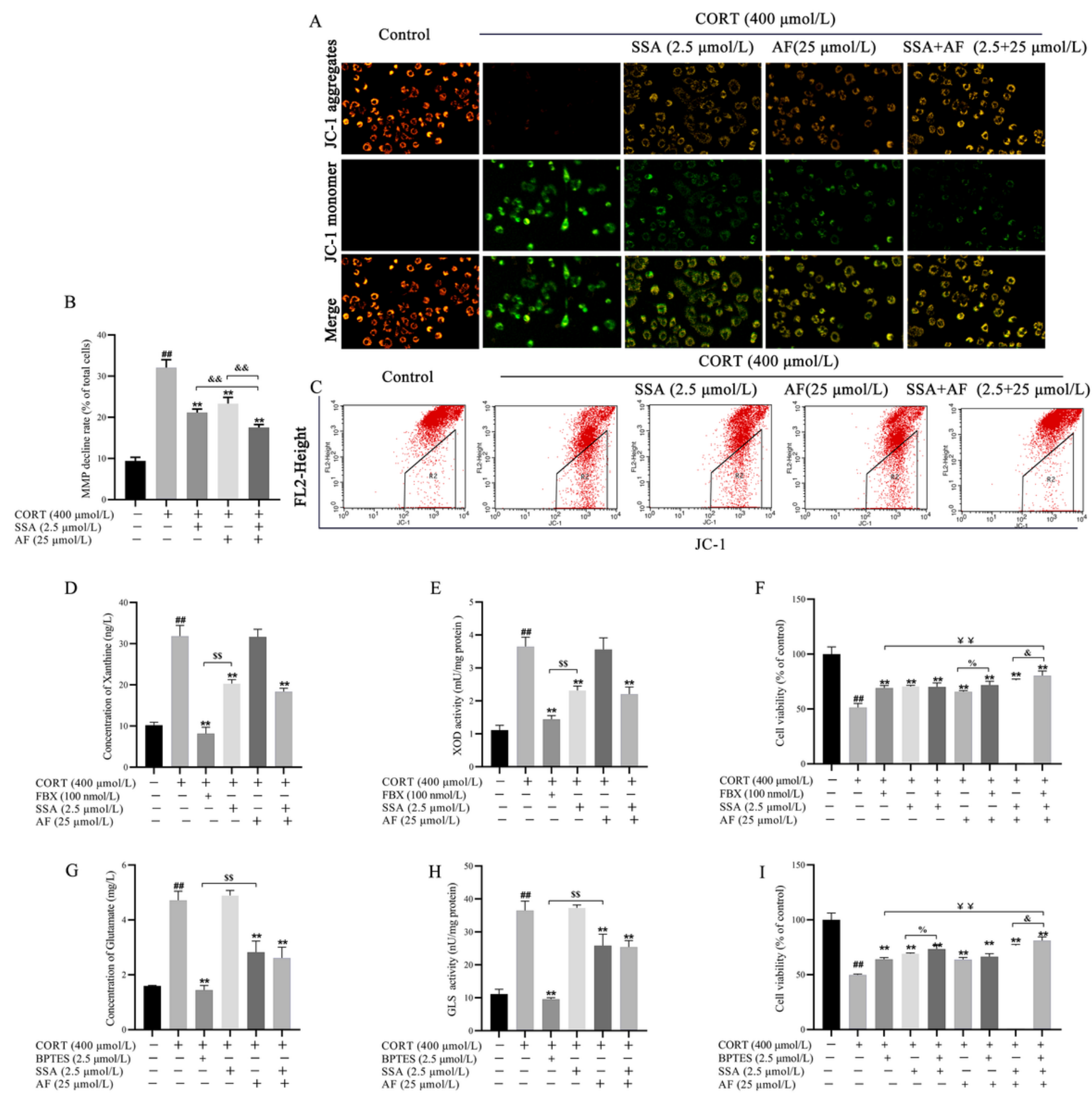

Figure 6

Effect of SSA and AF on TCA cycle, purine metabolism, and glutamate metabolism. (A/B/C) The effect of SSA and AF combination on the corticosterone-induced MMP decline $(n=3)$. (D) The levels of xanthine $(n=3)$. (E) The activity of XOD $(n=3)$. (F) The neuroprotection effects of FBX $(n=6)$. (G) The levels of glutamate $(n=3)$. (H) The activity of GLS $(n=3)$. (I) The neuroprotection effects of BPTES $(n=6)$. $(G / H / I)$. Data are expressed as means $\pm S D$. Data are expressed as a percentage of control and the results were expressed as the means $\pm \mathrm{SD}, \mathrm{n}=6$. \#\#P< 0.01 vs control group; $* * \mathrm{P}<0.01$ vs corticosterone group; $\$ \mathrm{P}<$ 
0.01 vs FBX group; \%P < 0.05 vs AF group; \&P < 0.05 vs SSA and AF combination group; \&\&P < 0.01 vs SSA and AF combination group; $\mathbb{Q} \mathrm{P}<0.01$ vs SSA and AF combination group. CORT: corticosterone, SSA: saikosaponin A, AF: albiflorin, FBX: febuxostat.
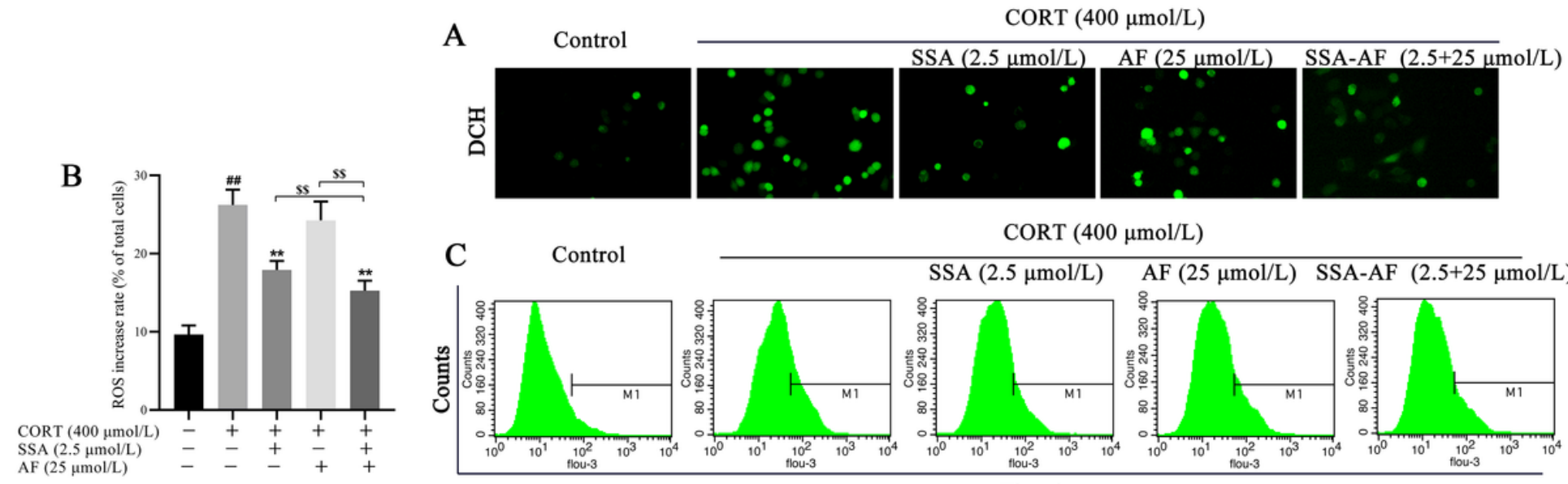

CORT $(400 \mu \mathrm{mol} / \mathrm{L})$
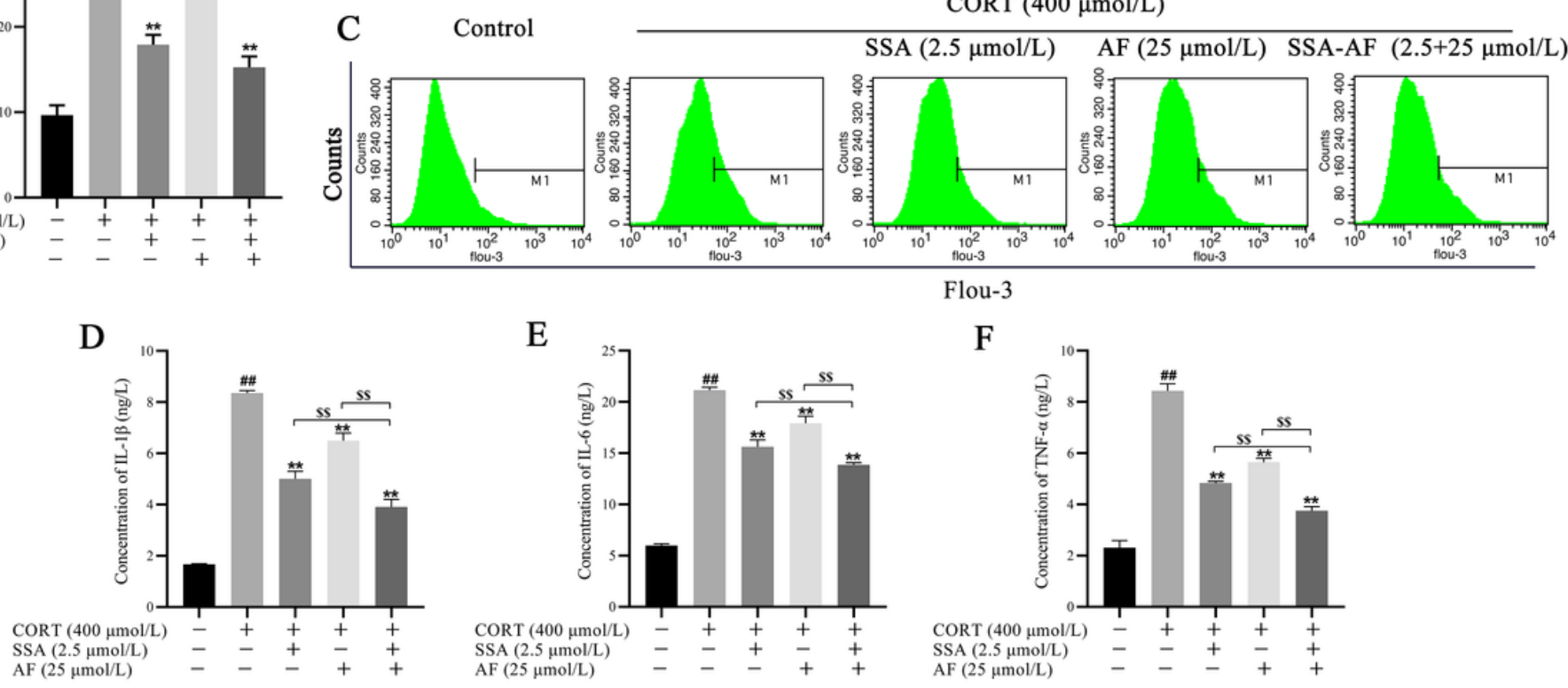

Flou-3
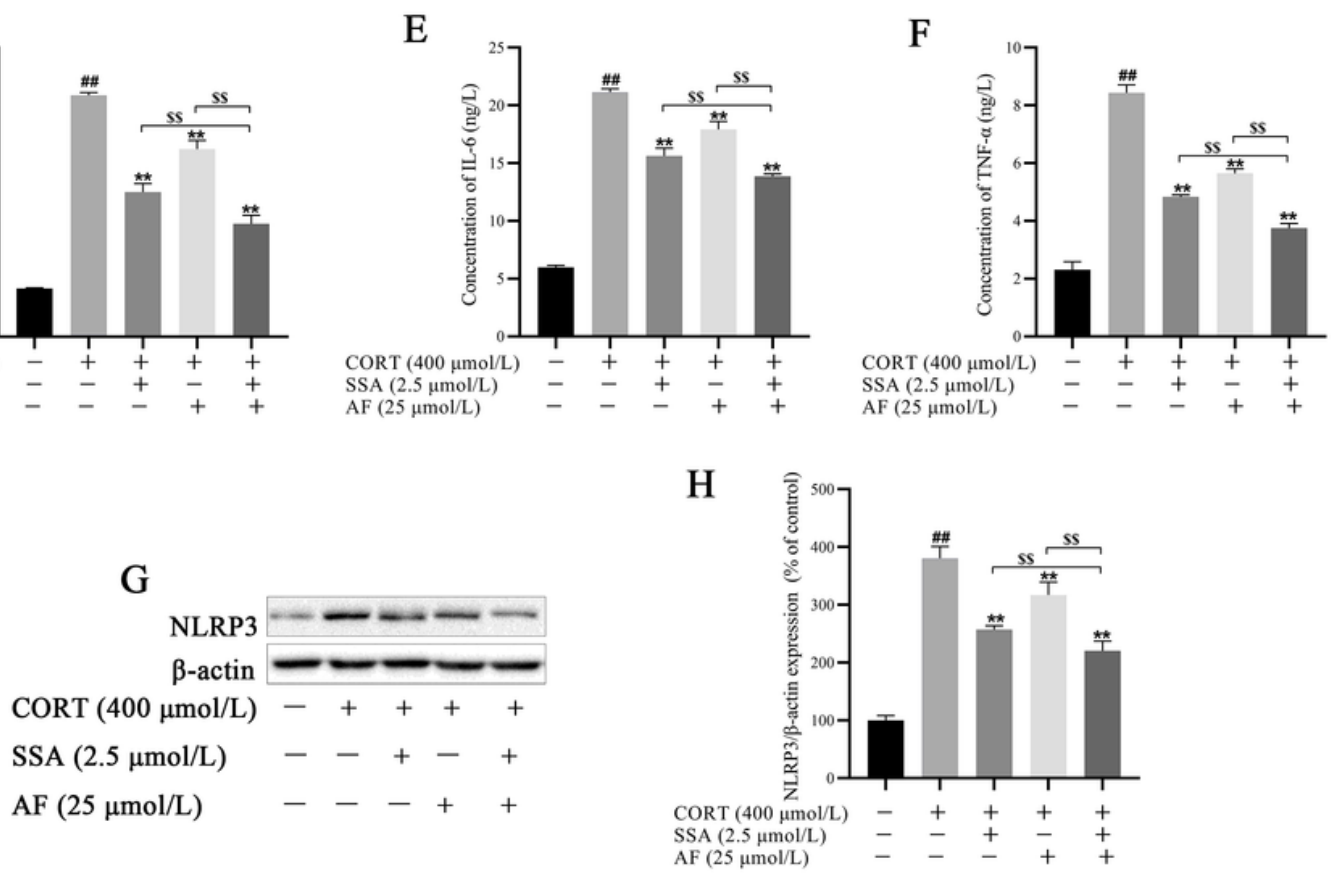

\section{Figure 7}

The effects of SSA and AF on oxidative stress and inflammation. (A) Representative DCFH-DA staining images of cell intracellular ROS. The photomicrographs in DCFH-DA staining, representative images of DCF-positive cells (green, high ROS level cells). (B/C) The levels of ROS ( $n=3)$. (D/E/F) The levels of IL-1 $I L-6$, and TNF- $a(n=3) .(G / H /)$ The expression level of NLRP3 $(n=3)$. Data are expressed as a percentage of control and the results were expressed as the means $\pm S D, n=6$. \#\#P<0.01 vs control group; $* * P<0.01$ vs corticosterone group; $\$ \$ P<0.01$ vs SSA and AF combination group. CORT: corticosterone, SSA: saikosaponin A, AF: albiflorin. 


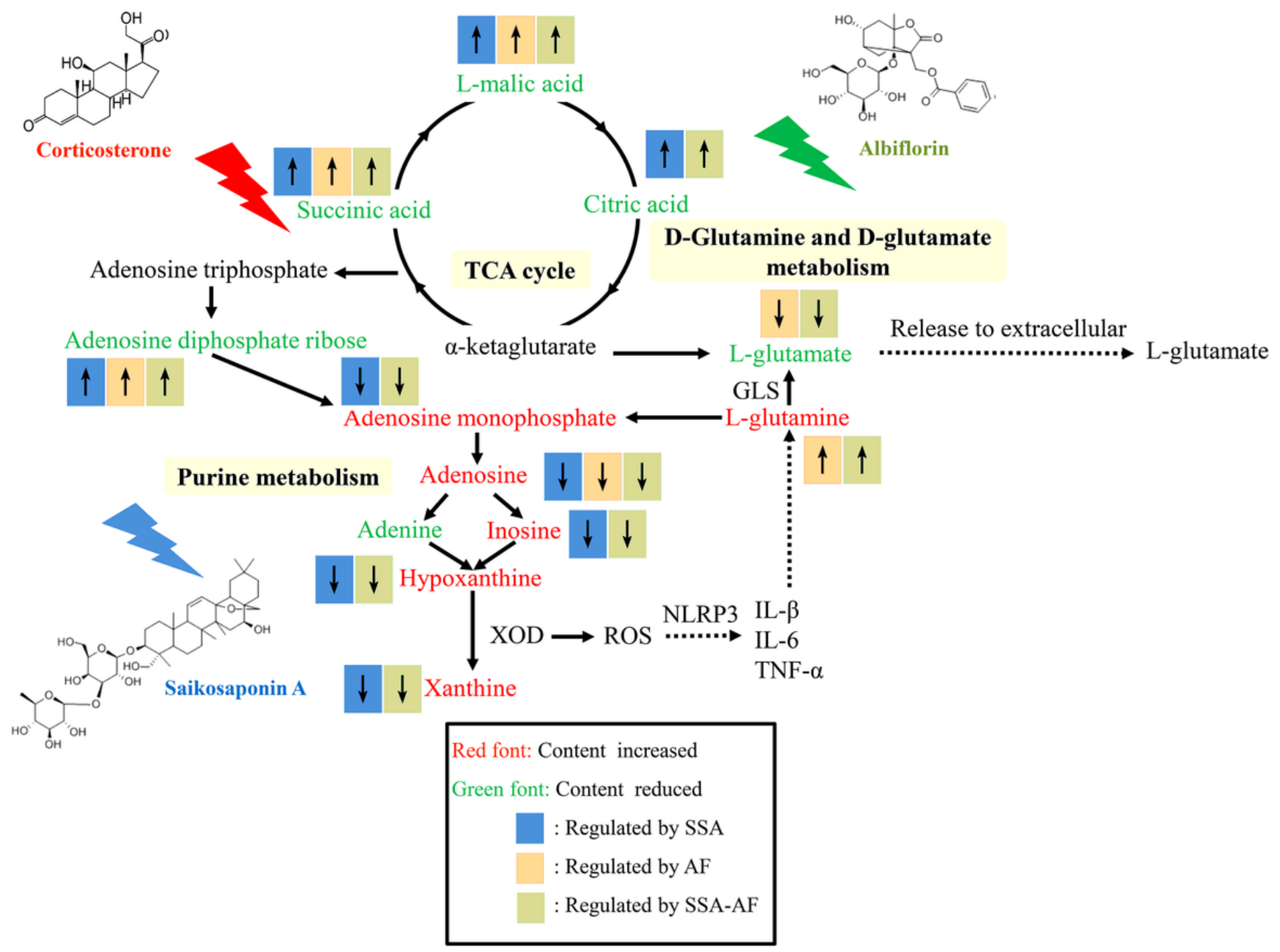

Figure 8

The schematic diagram illustrates the effects of SSA and AF on neuro-injury in corticosterone-induced PC12 cells.

\section{Supplementary Files}

This is a list of supplementary files associated with this preprint. Click to download.

- Graphicalabstract.tif

- Supplementarymaterial.docx 